\title{
Effect of $\delta$-phase on the Weldability and the Hot Ductility of Alloy 718
}

\author{
${ }^{1}$ Göran Sjöberg, ${ }^{2}$ Tomas Antonsson , ${ }^{3}$ Saied Azadian , ${ }^{3}$ Richard Warren and ${ }^{2}$ Hans Fredriksson \\ Volvo Aero Corporation, 46198 Trollhättan, Sweden \\ Royal Institute of Technology, 10044 Stockholm, Sweden \\ Malmö Högskola, 20506 Malmö, Sweden
}

Keywords: Alloy 718, weldability, $\delta$-phase, hot ductility

\begin{abstract}
In the weld repair cycles of alloy 718 the solution temperature is usually selected low enough to avoid grain growth in wrought material. At such low temperatures, however, $\delta$-phase also precipitates and the amount increases with each repair cycle.

It is well understood that the overall ductility is reduced by the presence of the $\delta$-phase in alloy 718 and, as such, may reduce the weldability. But it is also reported that the $\delta$-phase may cause incipient melting in grain boundaries at the heat affected zone, HAZ, through a niobium rich melt fed by the local abundance of this element from attached $\delta$-platelets. The purpose of the present work is to shed light on this issue on the one hand through practical weld experiments under heavily constrained circumstances and on the other through high temperature ductility testing in special hot tensile test equipment by which the hot ductility of re-melted material also was possible to examine. Materials with two levels of $\delta$-phase and with two grain sizes were included.

Contrary to what was anticipated it was extremely difficult to provoke cracking even in inhomogeneous cast material at the highest $\delta$-levels in heavily constrained TIG-weld experiments. Also the hot ductility test results, measured as the high temperature ductility recovery temperature and range, indicated that there is no or very limited deterioration by the presence of $\delta$-phase. Anomalous results, however, much lower ductility recovery temperatures, were found in samples with large grain size and a small amount of $\delta$-phase. For re-melted samples several hundred degrees lower recovery temperatures were measured.
\end{abstract}




\section{Introduction}

The approximately $5 \%$ niobium in alloy 718 enters as the principal hardening element into the $\gamma$ " precipitates, with the chemical composition $\mathrm{Ni}_{3} \mathrm{Nb}$ and with a body centered tetragonal (BCT) type of crystal structure, coherent with the face centered cubic (FCC) alloy matrix. The BCT phase has an inherent mismatch and the associated strain fields around the precipitates add considerably to the strengthening of the alloy. However, a thermal instability factor is inherent in the incoherence and alloy 718 is not recommended for high stress applications at temperatures above $650{ }^{\circ} \mathrm{C}$. This is one of the fundamental differences to the $\gamma$ ' type of superalloys where the $\gamma^{\prime}$ precipitates are of an ordered FFC type and with much less mismatch with the FCC matrix [1].

At temperatures slightly above the upper recommended temperature the $\delta$-phase, of body centered tetragonal (BCT) crystal structure, precipitates and growths into platelets [2]. The chemical composition of the $\gamma^{\prime \prime}$ and the $\delta$-phase is identical, $\mathrm{Ni}_{3} \mathrm{Nb}$, although with the different crystal structures and the latter can thus not precipitate without the dissolution of former - the $\delta$-phase is the stable one. Depending on the actual $\mathrm{Nb}$ content within the specification range, $4.75-5.5 \%$ by weight, the solution temperature for the $\delta$-phase varies from approximately 850 ${ }^{\circ} \mathrm{C}$ to $1050{ }^{\circ} \mathrm{C}$. With current $\mathrm{Nb}$ levels of wrought material today, with typically more than 5.2 $\%, \delta$ is still stable at $1000{ }^{\circ} \mathrm{C}$.

Since the $\delta$-phase reduces the amount of $\mathrm{Nb}$ available for $\gamma$ ' hardening and the amount has to be limited. Still a certain level is necessary for the grain size control in wrought material through its pinning effect during the manufacturing sequences. As a consequence, at solution heat treatments, prior to hardening, the temperature should not be so high that all $\delta$-phase dissolves, e.g. $1050{ }^{\circ} \mathrm{C}$, and temperatures around $950{ }^{\circ} \mathrm{C}$ are often used. At such temperatures, however, $\delta$ phase is not only stable but it also continues to precipitate at the typical Nb-levels mentioned. For each repair cycle involving welding on structural parts a solution and ageing process is needed to restore the full properties and the $\delta$-phase level increases with each cycle and may finally be unacceptable.

There are several reasons for limiting the acceptable amount of $\delta$-phase and first of all because it drains $\mathrm{Nb}$ from the matrix and reduces the strength achievable through the age hardening. Secondly, it is less ductile than the matrix which may be readily understood from the BCT structure, but, contrary to what the plate like morphological similarities with the topologically closed packed (TCP) phases of the $\gamma^{\prime}$ alloys may suggest, it is far from as brittle and it adheres well to the matrix allowing for significant deformation before the platelets separates from the matrix [3].

A third reason for limiting the amount of $\delta$-phase relates to its possible deteriorating effects on weldability [4] which is the purpose of the present paper to shed light on. In heavily constrained areas the reduced strain at fracture of material with high $\delta$-phase levels may lead to hot shortness and weld cracks. Of more fundamental concern has been possible incipient melting caused by preferential nucleation and precipitation of the $\mathrm{Nb}$-rich $\delta$-phase at grain boundaries. 


\section{Experimental}

\section{$\underline{\text { Cast material }}$}

Practical TIG weld experiments were carried out on hollow vanes excised from a retired large cast gas turbine structure under heavily constrained conditions, as illustrated in figure 1. Due to its inherent inhomogeneity cast alloy 718 is more susceptible to weld cracking than the wrought material. The actual chemical composition is given in table I together with that of the wrought material used for the hot tensile testing.

Table I. Chemical analysis in weight \% of the tested alloy 718 materials.

\begin{tabular}{|l|l|l|l|l|l|l|l|l|l|l|l|l|}
\hline & $\mathrm{Ni}$ & $\mathrm{Cr}$ & $\mathrm{Fe}$ & $\mathrm{Mo}$ & $\mathrm{Nb}$ & $\mathrm{Al}$ & $\mathrm{Ti}$ & $\mathrm{C}$ & $\mathrm{B}$ & $\mathrm{P}$ & $\mathrm{S}$ & $\mathrm{Ni}$ \\
\hline Structural Casting & Bal. & 18.9 & 18.3 & 2.94 & 4.93 & 0.46 & 0.94 & 0.05 & 0.004 & 0.009 & 0.004 & Bal. \\
\hline Wrought & Bal. & 17.7 & 18.3 & 2.88 & 5.12 & 0.50 & 0.97 & 0.02 & 0.003 & 0.006 & $<0.003$ & Bal. \\
\hline
\end{tabular}

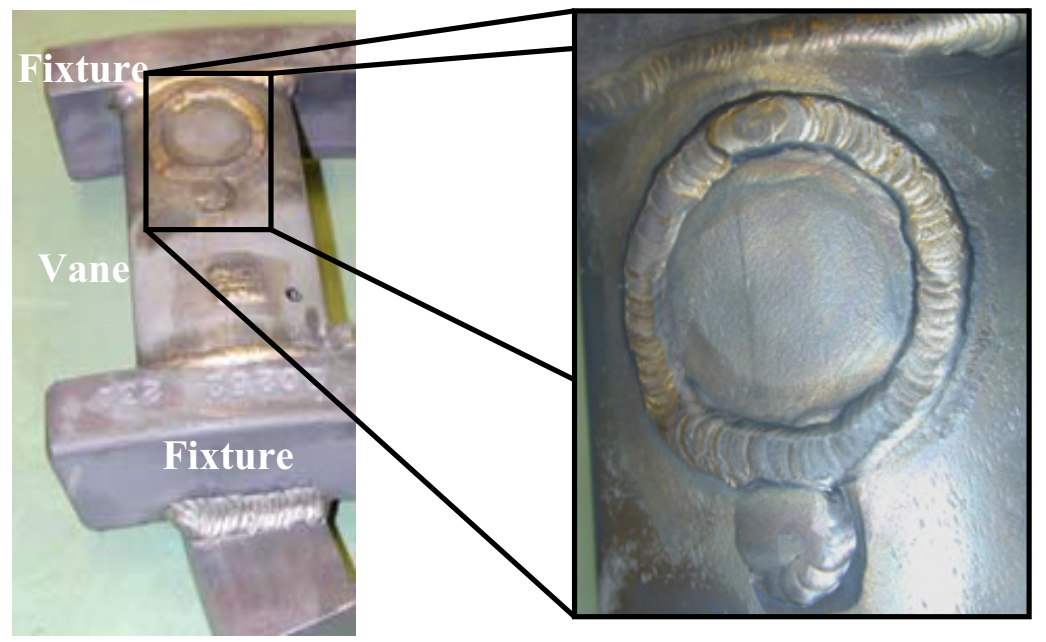

Figure 1 Heavily constrained welding arrangement with the vane welded into the fixture device before actual welding trials. To the right a close up view on a disk shaped piece of material TIG welded into a corresponding circular hole in the vane

As the purpose of this investigation is to evaluate the effect of $\delta$-phase, comparison was made of the material with different levels of this phase. A high level in this cast material was achieved after precipitation at $954{ }^{\circ} \mathrm{C}$ during 30 hours. With an additional heat treatment at $1040{ }^{\circ} \mathrm{C}$ for 2 hours virtually all of this $\delta$-phase was dissolved as seen in figure 2 . The uneven distribution of the phase reflects the strong tendency for segregation of the niobium in the casting process to locations in the vicinity of grain boundaries where solidification terminates. 

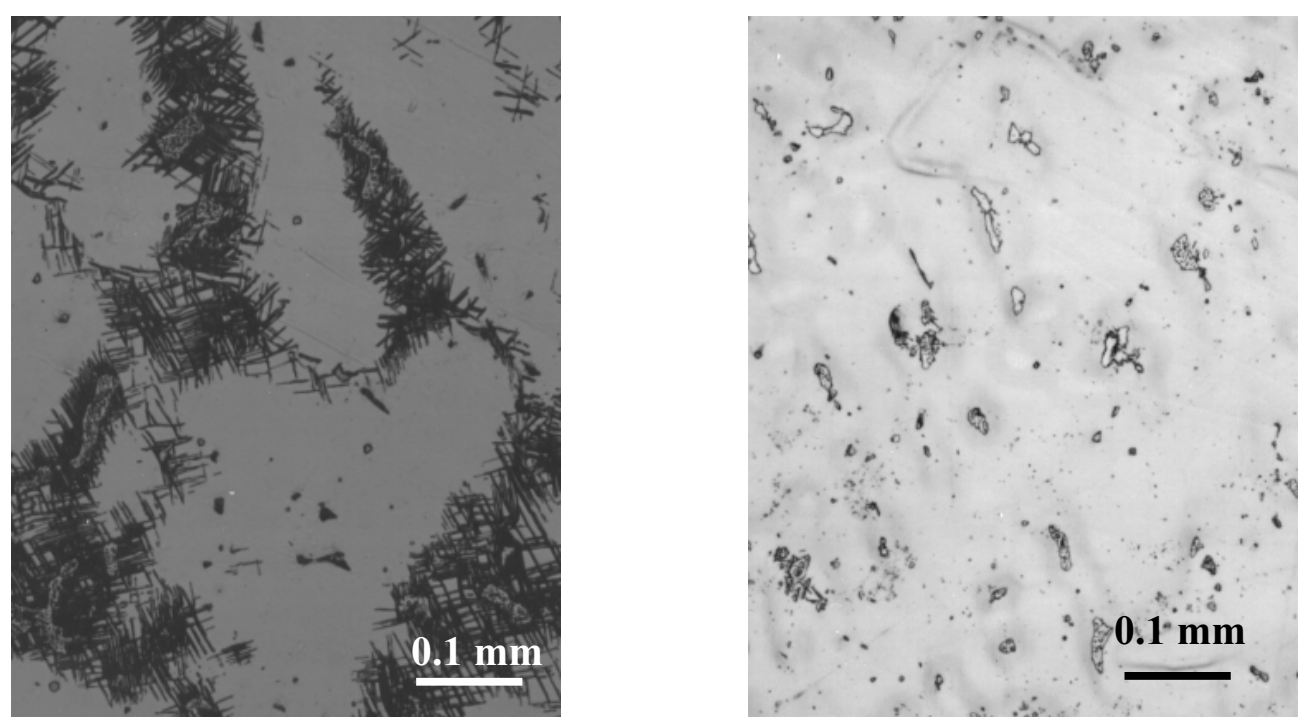

Figure 2 Preferential precipitation of $\delta$-phase at grain boundaries in the cast material after 30 hours at $954{ }^{\circ} \mathrm{C}$ (left) and followed by a 2 hours solution at $1040{ }^{\circ} \mathrm{C}$ (right).

\section{$\underline{\text { Wrought material }}$}

The wrought material for hot tensile testing was heat treated into a fully solutioned, $\delta$-free, state and into a high level $\delta$-phase state both with two different grain sizes and also into a large grain state with a limited amount of $\delta$-phase as shown in table II.

Table II. Heat treatments and microstructure before hot tensile testing.

\begin{tabular}{|c|c|c|}
\hline Acronym & Heat treatment & Microstructure after heat treatment \\
\hline $\begin{array}{l}\text { LG } \\
\text { (Large Grain) }\end{array}$ & $1100^{\circ} \mathrm{C} 1 \mathrm{~h}$, furnace cooling & Homogenous $\gamma$, GS $150-200 \mu \mathrm{m}$ \\
\hline $\begin{array}{l}\text { SG } \\
\text { (Small Grain) }\end{array}$ & $1040^{\circ} \mathrm{C} 1 \mathrm{~h}$, water quench & 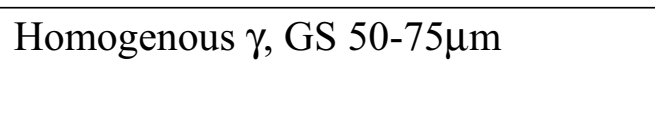 \\
\hline $\begin{array}{l}\text { SGD } \\
\text { (Small Grain Delta) }\end{array}$ & $\begin{array}{l}1040^{\circ} \mathrm{C} 1 \mathrm{~h}, \text { water quench, } \\
900^{\circ} \mathrm{C} 24 \mathrm{~h}, \text { water quench }\end{array}$ & 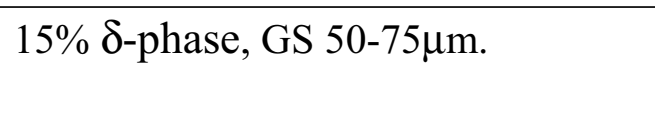 \\
\hline $\begin{array}{l}\text { LGD } \\
\text { (Large Grain Delta) }\end{array}$ & $\begin{array}{l}1100^{\circ} \mathrm{C} 1 \mathrm{~h} \text {, water quench, } \\
900^{\circ} \mathrm{C} 24 \mathrm{~h} \text {, water quench }\end{array}$ & $12 \% \delta$-phase $\delta$, GS $150-200 \mu \mathrm{m}$ \\
\hline $\begin{array}{l}\text { LGLD } \\
\text { (Large Grain Limited Delta) }\end{array}$ & $\begin{array}{l}1100^{\circ} \mathrm{C} 1 \mathrm{~h}, \text { furnace cooling, } \\
960^{\circ} \mathrm{C} 24 \mathrm{~h} \text {, furnace cooling }\end{array}$ & $\begin{array}{l}2 \% \text { coarse } \delta \text {-platelets, frequently at } \\
\text { grain boundaries, GS } 150-200 \mu \mathrm{m}\end{array}$ \\
\hline In-situ melted & none & As in the delivery condition \\
\hline
\end{tabular}

(Carbides and nitrides are present in all specimens and not affected by any heat treatments except for the in situ melted samples) 
The microstructure of the small grain (SG) specimens without $\delta$-phase shown in figure $3 \mathrm{a}$ also illustrates the microstructure of the large grain (LG) specimens. The $\delta$-phase level shown in figure $3 \mathrm{~b}$ of the small grain $\delta$-phase (SGD) specimens similarly illustrates the level of the large grain $\delta$ (LGD) specimens. The microstructure of the large grain material with limited amount of $\delta$-phase (LGLD) is shown in figure 3c.
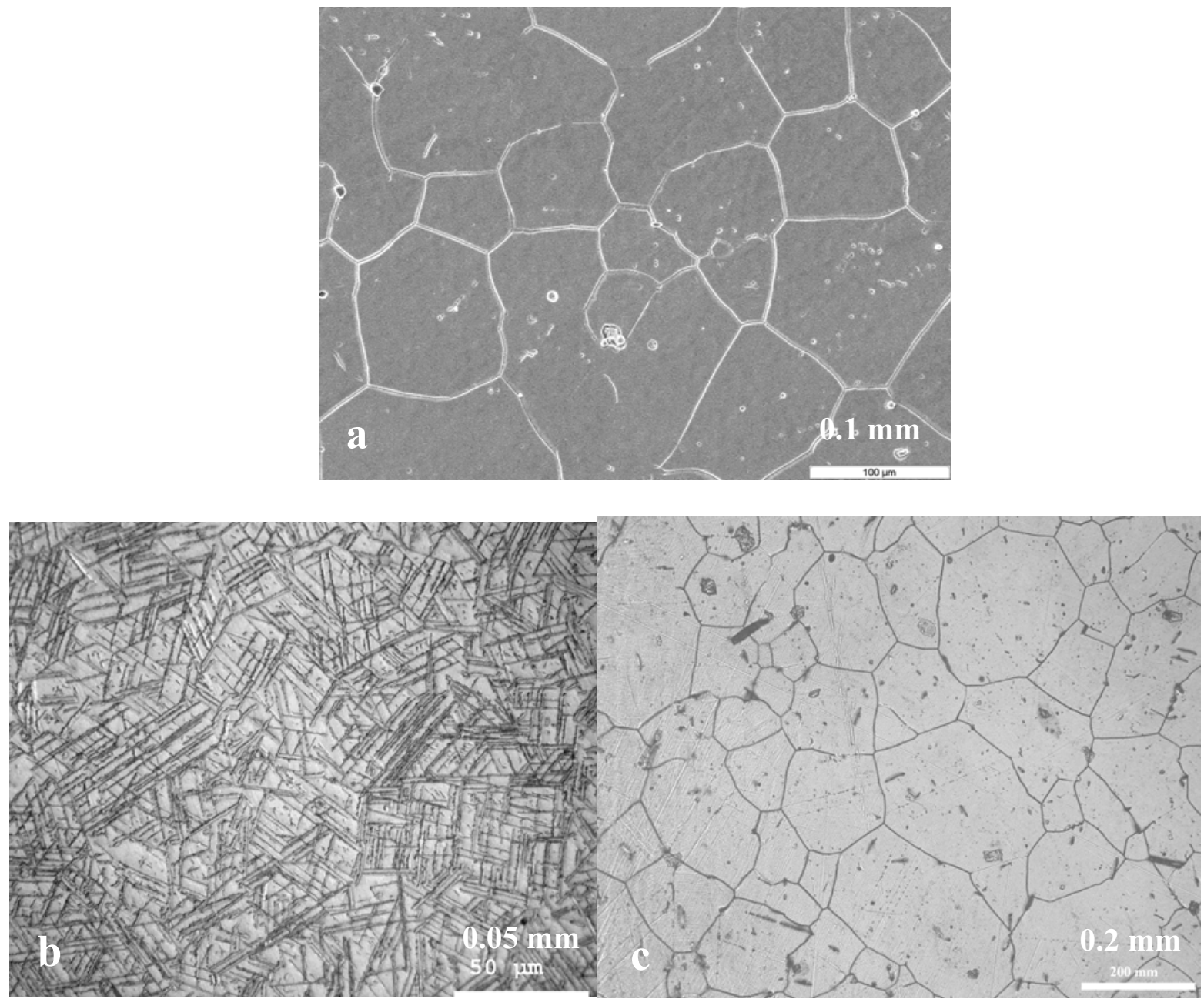

Figure 3. Typical microstructures of the examined wrought material after specific heat treatments. a) Fully solutioned after 1 hour at $1040{ }^{\circ} \mathrm{C}(\mathrm{SG})$. b) Same material as in fig a but with an additional $900^{\circ} \mathrm{C} 24$ hours $\delta$-phase precipitation heat treatmen (SGD). c) Grain growth at $1100{ }^{\circ} \mathrm{C}$ for 1 hour followed by limited $\delta$-phase precipitation at $960{ }^{\circ} \mathrm{C}$ during 24 hours (LGLD).

The hot ductility testing was performed in an equipment especially developed for the study of strength and ductility during melting and solidification of metals at the Department of Casting Technology at The Royal Institute of Technology in Stockholm, Sweden, [5] schematically shown in figure 4. 

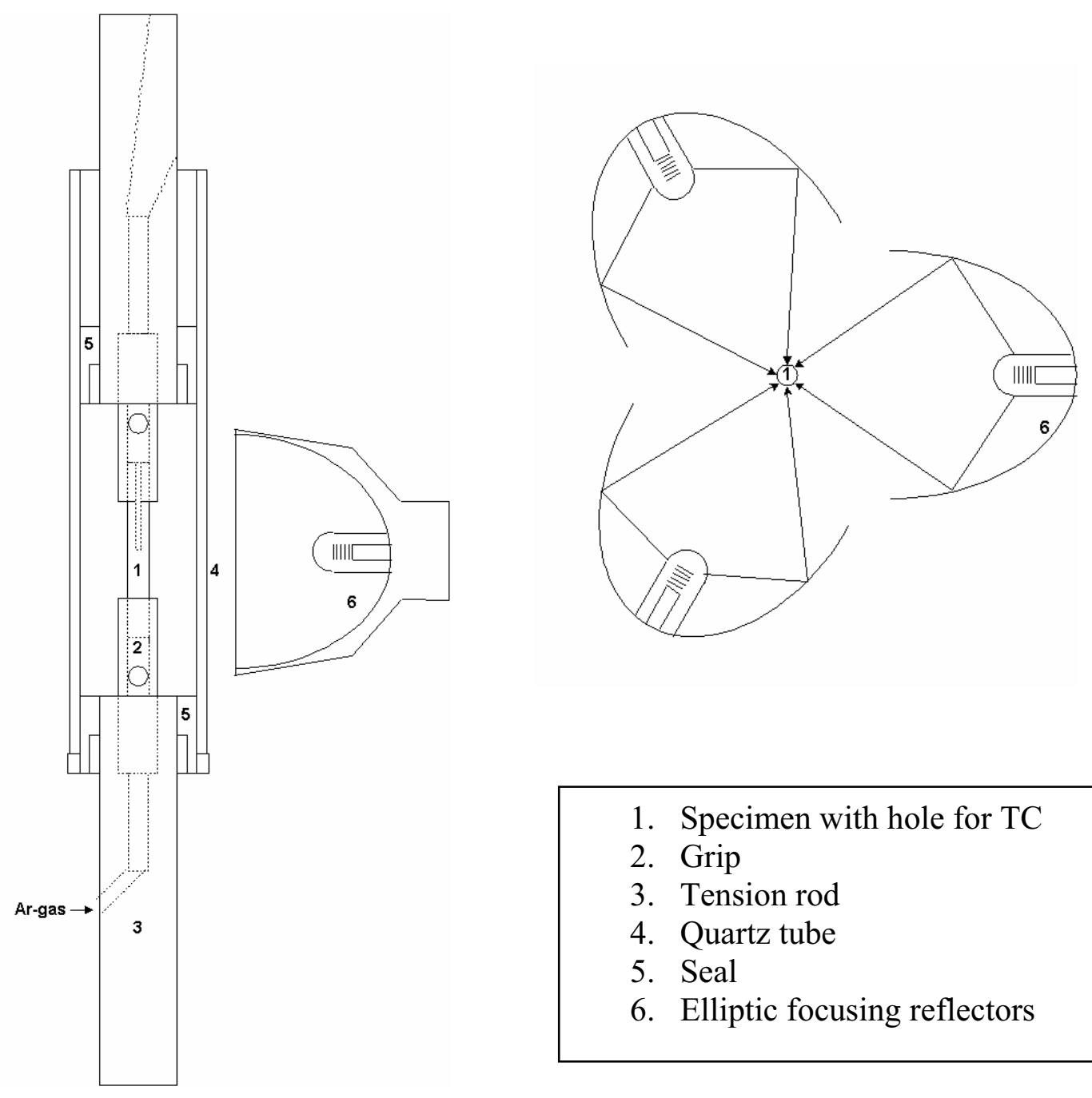

Figure 4. Hot tensile test equipment and specimen geometry.

Due to the small dimensions of the specimens, $4 \mathrm{~mm}$ diameter and $40 \mathrm{~mm}$ length, and a good focusing power of the elliptic $1 \mathrm{~kW}$ mirror furnace a heating rate of $300^{\circ} \mathrm{C} / \mathrm{min}$ as well as a cooling rate of $400{ }^{\circ} \mathrm{C} / \mathrm{min}$ was possible to use in our experiments. For the same reasons it was possible to melt a limited amount of material at the center of the specimen with an approximate length of the heated zone of $5 \mathrm{~mm}$, a droplet melt which was kept in position by surface tension and thus enabled the study of the full temperature range of the welding process. The temperature measurements were made by a (Pt-PtRh) thermocouple located in a hole centered in each specimen. During the testing, the specimens were located inside a quartz tube and protected by a flow of pure argon gas.

The span between the temperature where the material loses its strength completely on heating, the zero strength temperature (ZST), and the temperature when the material has recovered the ductility during cooling, the ductility recovery temperature (DRT) was used as a measure of the susceptibility to cracking in the HAZ. Such a temperature span is logical to use in the sense that the larger this interval, with the material in a 'brittle' state, the larger is the risk for cracks to 
develop in the heat affected zone of the material when subjected to strain during the cooling down phase of the welding process.

The heating and cooling cycle at testing is schematically illustrated in figure 5 . The specimens were heated to $10-20^{\circ} \mathrm{C}$ below the zero strength temperature, ZST, determined for each type of material by heating the sample at rate of $5^{\circ} \mathrm{C} / \mathrm{s}$ with an applied load of $50 \mathrm{~N}$, until the samples fractured. The in situ solidified specimens were for several practical reasons tested according to another cycle as also seen in figure 5 .
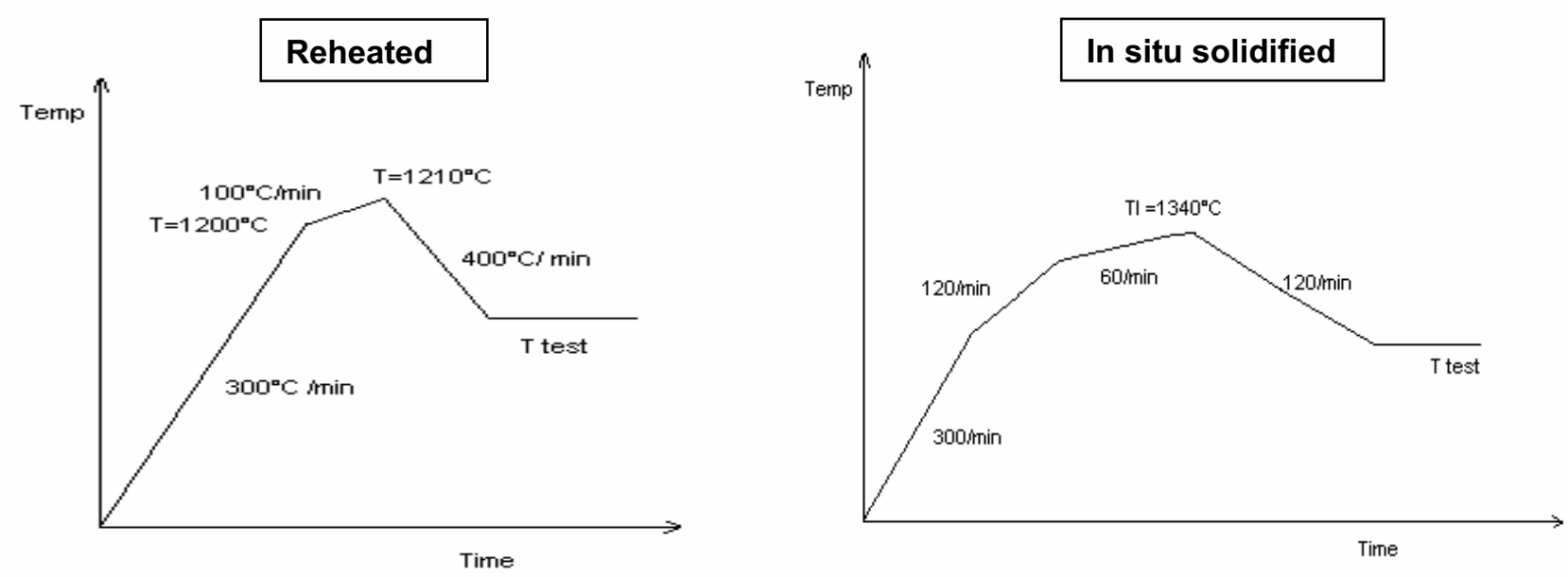

Figure 5. Schematic heating and cooling cycle at testing of reheated specimens with specific microstructures to the left and the cycle used for the in situ solidified specimens to the right

The strain rate during the testing was set by the $0.5 \mathrm{~mm} / \mathrm{s}$ tension rod rate, which corresponds to an approximate strain rate of $0.1 \mathrm{~s}^{-1}$, assuming that the length of the deformed zone was the same as the length of the heated zone, i.e. $5 \mathrm{~mm}$.

Evaluation of microstructures and fracture surfaces were made by standard metallographic techniques including SEM and EDS.

\section{Results}

\section{Practical weld experiments on cast material}

As mentioned it was very difficult to provoke any cracking in the heavily constrained weld experiments on the ex-service cast vanes. Nor by penetrant inspection neither by x-ray examination was it possible to detect any cracking. However, after extensive successive metallographic examination one crack in the vane without $\delta$-phase and one crack in the vane with $\delta$-phase were possible to detect in the HAZ adjacent to the weld material, both in the millimetre size region. 
The ZST for the different materials was determined by heating the sample at a rate of $5{ }^{\circ} \mathrm{C} / \mathrm{s}$ with an applied load of $50 \mathrm{~N}$, until the samples fractured. For the two materials containing large amount of $\delta$-phase ZST was found to be $1223{ }^{\circ} \mathrm{C}$ and for the material without $\delta$-phase (including the material with the very limited amount) it was found to be $1234{ }^{\circ} \mathrm{C}$ while for the in situ melted material the ZST was established to be $1238^{\circ} \mathrm{C}$.

During the ductility recovery tensile testing the peak temperature was chosen $10-20{ }^{\circ} \mathrm{C}$ below ZST before the cooling down and testing at the specified testing temperatures as indicated in figure 5 .

The actual ductilities measured by the reduction of area for the different materials are shown in figure 6 . Ductility for the materials with high amounts of $\delta$-phase (figure $3 \mathrm{~b}$ ) and without any $\delta$ phase is rapidly recovered and reach $100 \%$, all within $100{ }^{\circ} \mathrm{C}$ from the ZST. However, the material with the large grains with a limited amount of $\delta$ does show a significantly lower temperature for the return of the ductility, actually at a more than $100{ }^{\circ} \mathrm{C}$ lower temperature. Finally, in the in situ solidified material there is a limited ductility which arrives first at very low temperatures.

\section{Area reduction-Temperature on Cooling}

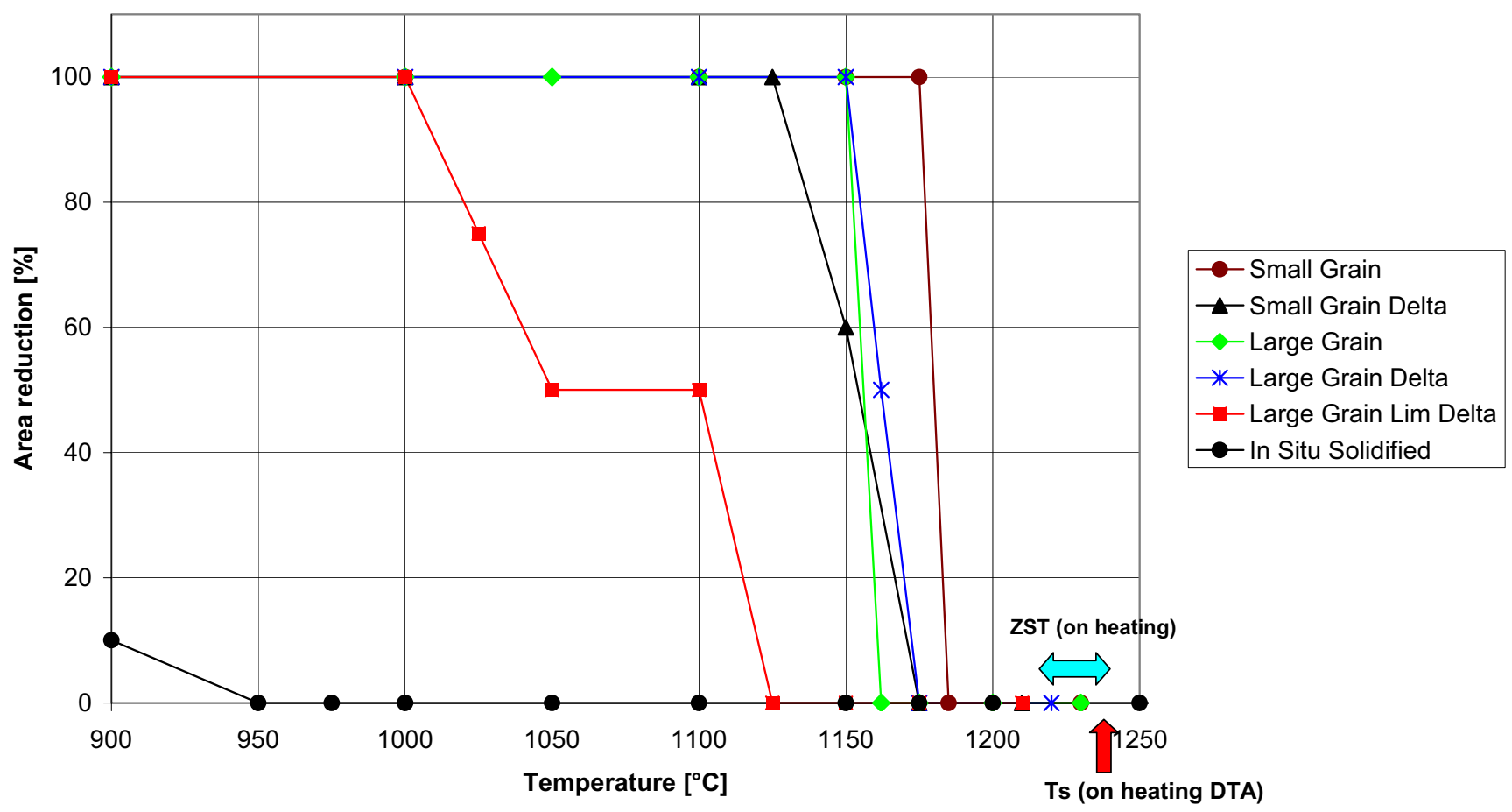

Figure 6. Ductility of the different states of the wrought material after testing at specified temperatures on cooling from the zero strength temperature and measured as area reduction.

For the in situ solidified material and the small grain material with and without $\delta$-phase the gradual return of the ultimate tensile when temperature decreased were, at what first may seem surprisingly, similar as shown in figure 7 . However, at the very high temperature testing the yield or rather creep stress is basically determined by the resistance to dislocation mobility through by 
the chemistry and with the microstructural features like grain size having a secondary influence. Ultimate stress is reached instantaneously considering the very limited amount of material involved ( $4 \mathrm{~mm}$ diameter $\mathrm{x} 5 \mathrm{~mm}$ heated length) followed by either necking or brittle fracture.

\section{Maxium Force on Cooling}

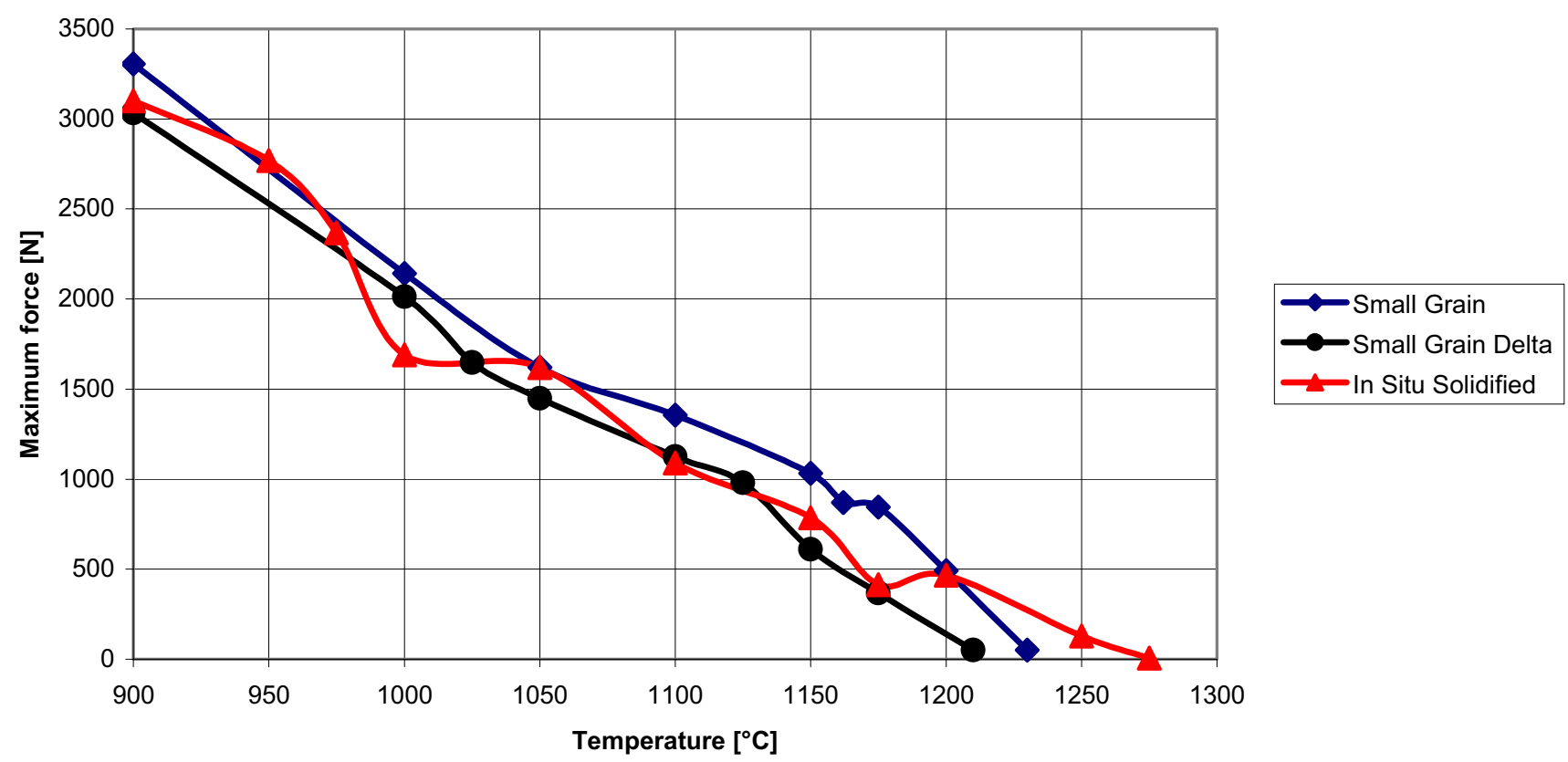

Figure 7. Maximum force registered during the tensile testing at the selected temperatures after cooling from the zero strength temperature.

Typical appearances of fractured specimens at full ductility and at zero ductility are shown in figure 8 . In the figure the material with large grains and without $\delta$-phase, tested at $1050{ }^{\circ} \mathrm{C}$ and at $1162{ }^{\circ} \mathrm{C}$, respectively, are used for illustration.
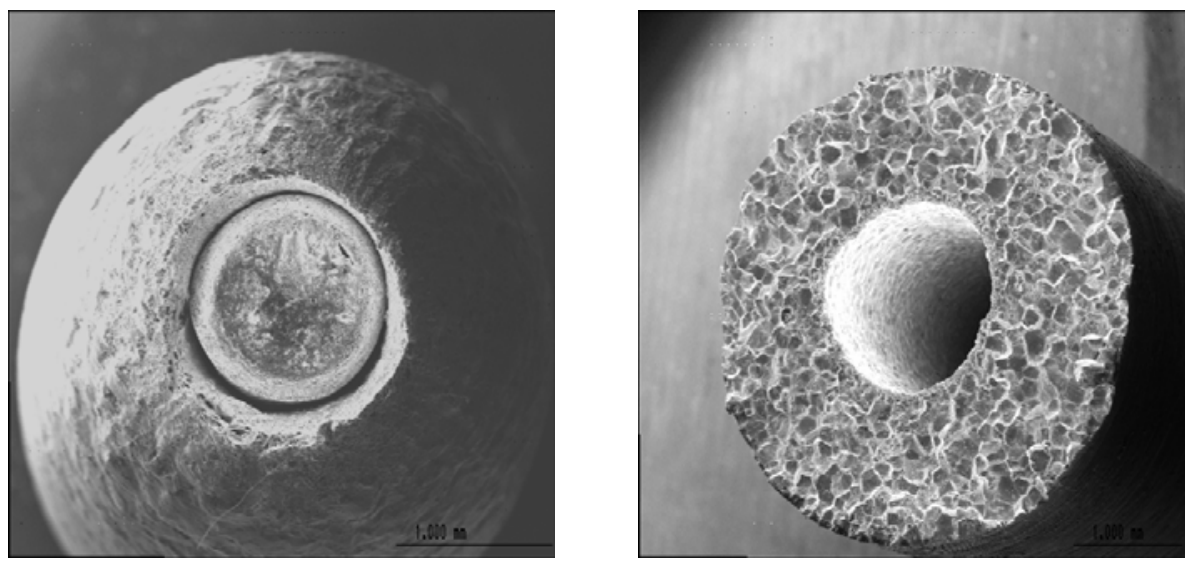

Figure 8. Typical appearances of fractured specimens with full ductility and with no ductility at the testing. The fracture surfaces of the material with large grains and without $\delta$-phase tested at

$1050{ }^{\circ} \mathrm{C}$ with $100 \%$ ductility and at $1162{ }^{\circ} \mathrm{C}$ with $0 \%$ are shown to the left and to the right, respectively, are here used for illustration. In the ductile specimen the thermocouple, diameter 1 $\mathrm{mm}$, remains in the position of the testing while it has been pulled out from the brittle specimen after the testing. 


\section{Discussion}

The results from the practical weld experiments on cast material as shown in figure 1 confirms the excellent weldability of alloy 718 . Since the niobium is very strongly segregated to the grain boundaries in the cast material the precipitated $\delta$-phase also accumulates to the vicinity of the grain boundaries, as shown in figure 2 . Thus, any deterioration effect of the $\delta$-phase on weldability involving intergranular fracture in the HAZ must be more pronounced in cast material in comparison with wrought material with the same total amount of $\delta$-phase present since the niobium segregation is much less pronounced in the wrought material where the much finer grain structure adds to the crack resistance. From this rational we may draw the conclusion, although no welding experiments were conducted, that wrought material should be able to sustain much more $\delta$-phase than cast material without causing any weldability problems.

The results from the tensile testing on the wrought material support this conclusion. Looking first into the group of four materials containing the large grain and small grain material without $\delta$ phase and the same two materials with a large amount of $\delta$ they all recover the ductility within $100{ }^{\circ} \mathrm{C}$ from the zero strength temperature and this indicates a good weldability.

Let us now consider the details of the tensile test results. The ductility of the fine grain material without $\delta$-phase $\delta$ returns at significantly higher temperatures when compared with the same but large grain size material and this reflects the well known better weldability of materials with a fine grain size. Ductility returns slightly more gradually in the materials containing large amount of $\delta$-phase as compared with the sluggish return in the materials without $\delta$-phase. It also seems as if the $\delta$-levels out the effect of the grain size. A conclusion may here be that the presence of $\delta$-phase does not add to the deterioration of the weldability already induced by an increased grain size, but data is limited. Another conclusion that may be drawn is that small grain material with $\delta$-phase is worse from a welding point of view than the large grain material with $\delta$-phase but here the data are even scarcer and in addition it is difficult to find a rational explanation that supports such a conclusion.

The part of the tensile test results which we find most difficult to explain is the ductility return curve for the material where the $\delta$-phase precipitation temperature was $960{ }^{\circ} \mathrm{C}$ instead of $900{ }^{\circ} \mathrm{C}$ producing a very limited, but in comparison, very coarse $\delta$-phase at the grain boundaries as seen in figure 3. If the amount of $\delta$ can be considered to have a detrimental effect on the ductility recovery temperature one would have expected to see the material with a higher $\delta$-phase content to have the ductility return at a lower temperature. Now we see the opposite. Although we are not able to draw any final conclusions from these anomalous results the metallographic examination of the fractured test bars may shed some light on the issue.

In figure 9 features of the brittle fracture surface of the material with the limited amount of $\delta$ are shown from a specimen tested at $1150{ }^{\circ} \mathrm{C}$. In the low magnification (9a) the intergranular fracture character is obvious with secondary cracks clearly visible. What may be the explanation for the anomalous behaviour of this material is a conclusion that can be drawn from the higher magnification micrograph $9 \mathrm{~b}$. It is here evident from the dark patches (two larger pointed out by the white arrows) that a liquid phase with a good wetting capacityty was present during the fracture process. Although it was not possible to analyse by EDS the dark appearance, presumably given by the atomic number contrast, indicates that atoms of low atomic number constitute a significant part of the composition. In these circumstances sulphur or boron may be candidates - both eluding EDS analysis and both capable of producing very low melting 
compounds and known to have a deleterious influence on weldability. However, we have no explanation to why such phases would appear during the 24 hour heat treatment at $960{ }^{\circ} \mathrm{C}$ but neither at a higher $\left(1\right.$ hour at $\left.1040{ }^{\circ} \mathrm{C}\right)$ nor at a lower $\left(24\right.$ hour at $\left.900{ }^{\circ} \mathrm{C}\right)$ temperature. In the other high magnification micrograph (9c) indications of another liquid phase of lower contrast is seen. What is seen here may be traces of what was the basic concern of our investigation and the suggestions in the literature that $\delta$-phase at grain boundaries during the welding process may supply niobium for constitutional liquation through the Laves eutectic. In figure 10c traces of the thinner $\delta$-platelets of the small grain material can still be seen after the tensile testing. This observation supports the possibility that the niobium rich area which remains after the fast solution of the thin $\delta$-platelets may give enrichment for such a constitutional Laves phase eutectic formation. The coarser platelets precipitated at $960{ }^{\circ} \mathrm{C}$ and at the grain boundaries should be even more powerful in this respect.
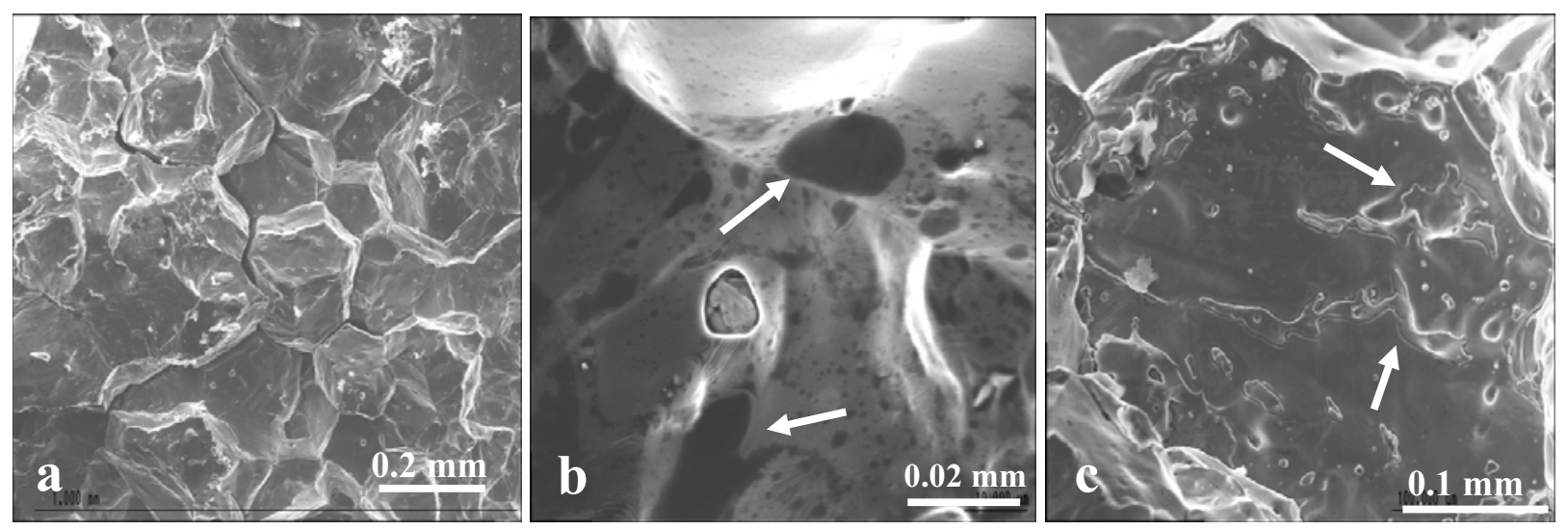

Figure 9. Features of the brittle fracture surface of the material with the limited amount of $\delta$ phase from the specimen tested at $1150{ }^{\circ} \mathrm{C}$. a) Intergranular fracture surface with secondary cracks. b) Traces of wetting liquid with low atomic number element contrast. c) Traces of possible high niobium melt.

For comparison, the fracture surface from a brittle fracture of the small grain material (1 hour solution at $\left.1040^{\circ} \mathrm{C}\right)$ with a large amount of $\delta$-phase $\left(24\right.$ hour at $\left.900^{\circ} \mathrm{C}\right)$ is shown in figure 10 . The specimen was tested at $1075^{\circ} \mathrm{C}$ with zero ductility. In the lower magnification (10a) the intergranular character of the fracture is evident but much less pronounced than for the anomalous material shown in figure 9. The irregular topography of the surface (10a and b) indicates a certain local deformation during the fracture process as does the secondary cracks below the fracture surface (10c). The grain boundary cohesion is here stronger but not so strong as to allow for any measurable overall plastic deformation before fracture. At the fracture surface there are also a few isolated patches with evident low grain boundary cohesion(10b). In our investigation of this material it was however not possible to attach any cause to these features. In all, our results stresses the importance of understanding the grain boundary chemistry and reactions involved in all the temperature exposure of super alloys prior and during the welding process. Of special importance are grain boundary active elements like sulphur, phosphorus and boron and segregation and partitioning in connection with secondary phases - complex relations which must be in focus when optimizing weldability of 718 type and other types of superalloys. 

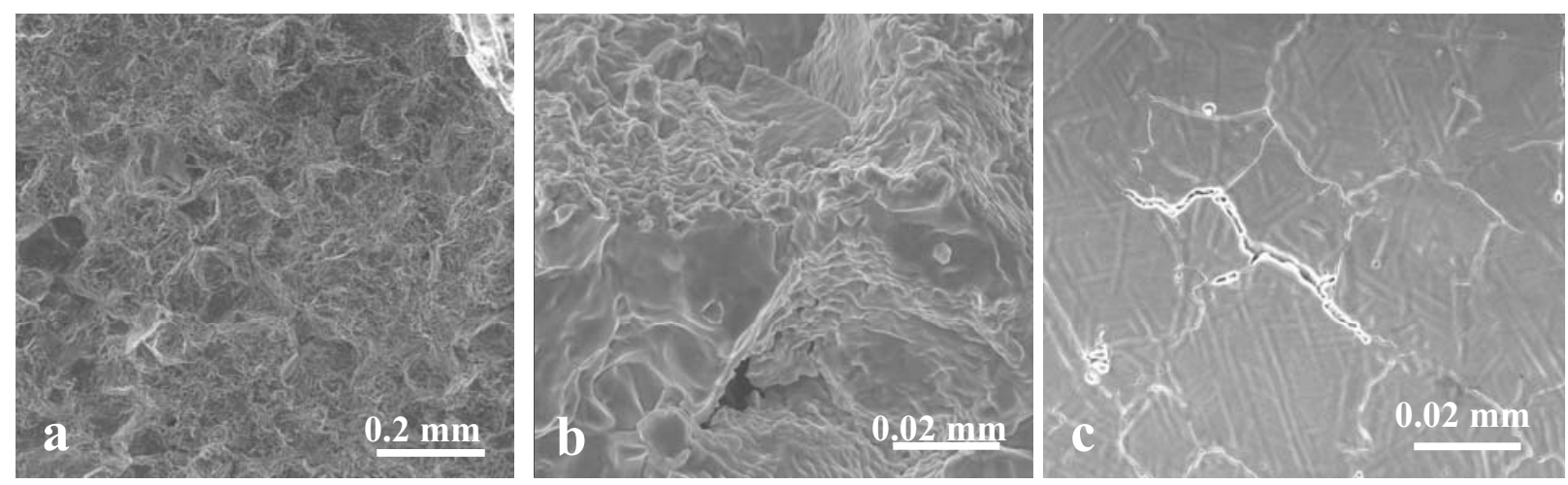

Figure 10. The brittle fracture surface (10a and 10b) and a cross section close to the fracture surface $(10 \mathrm{c})$ of the small grain material $\left(1\right.$ hour solution at $\left.1040^{\circ} \mathrm{C}\right)$ with a large amount of $\delta$ phase $\left(24\right.$ hour at $\left.900{ }^{\circ} \mathrm{C}\right)$ tested at $1075^{\circ} \mathrm{C}$ with zero ductility. a) Intergranular fracture with micro-level grain boundary ductility. b) Isolated patch of low grain boundary coherence in micro-ductile surroundings. c) Grain structure close to the fracture surface with a secondary crack and traces of solutioned $\delta$-platelets

\section{Conclusions}

- The presence of $\delta$-phase has minimal if any effect on the weldability of alloy 718 .

- Anomalous, low hot ductility, behaviour of wrought material after precipitation of $\delta$ phase at $960^{\circ} \mathrm{C}$ for 24 hours is associated with the occurrence of a liquid with good ability to wet grain boundaries.

\section{Acknowledgements}

KME, Sweden supported the major part of the work in this paper. Special thanks to coop student Robert Söderberg for the work involving the weldability of the cast ex-service material.

\section{References}

1 C.T. Sims and W.C. Hagel, “The Superalloys, Wiley, New York, 1972, 171-178.

2 S. Azadian, "Aspects of Precipitation in the Alloy Inconel 718" (Ph.D. thesis, Luleå University of technology, Sweden, 2004), 71-83.

3 G. Sjöberg and N-G. Ingesten, "Grain Boundary $\delta$-phase Morphologies, Carbides and Notch Rupture Sensitivity of Cast Alloy 718", Superalloys 718, 625, 706 and Various Derivatives, Loria, E. A. ed., (The Minerals, Metals \& Materials Society, 1991), 603-620.

4 M.E. Mehl and J.C. Lippold, "Effect of $\delta$-phase Precipitation on the Repair Weldability of Alloy 718", Superalloys 718, 625,706 and Various Derivatives, Edited by E.A. Loria, (The Minerals, Metals \& Materials Society, 1997), 731 -741.

5 Tomas Antonsson, "On the Interaction Between Liquid/Solid During Sintering and Solidification" (Ph.D. thesis, Royal Institute of Technology, Sweden, 2003), Suplement 8. 